Vol.4, No.2, Desember 2020

e-ISSN: 2548-6853

\title{
PERANCANGAN MOTION GRAPHIC IKLAN LAYANAN APLIKASI GARUDA KASIR SEBAGAI MEDIA PROMOSI DI SOSIAL MEDIA
}

\author{
Syarifah Shakila Alatas \\ Teknik Multimedia \& Jaringan, Politeknik Negeri Batam
}

\begin{tabular}{l} 
Article Info \\
\hline Article history: \\
Received Oct $26^{\text {th }}, 2020$ \\
Revised Nov $19^{\text {th }}, 2020$ \\
Accepted Dec $10^{\text {th }}, 2020$ \\
\hline
\end{tabular}

Keyword:

Layanan Informasi

Media Promosi

Motion Graphic

Media sosial

\begin{abstract}
ABSTRAK
Program bimbingan yang tidak memberikan layanan informasi akan mengahalangi setiap mahasiswa untuk berkembang lebih jauh, karena mereka juga ingin berkesempatan untuk mempelajari dan memahami info yang diberikan. Namun, mengetauhi luasnya info yang dibagikan, mereka juga harus mengetahui informasi manakah yang jelas untuk mereka dan mana yang tidak jelas, serta jenis informasi apa yang berhubungan mctentang layanan dan fakta yang tidak berubah dan yang dapat berubah dengan berjalannya waktu. Solusi yang akan di gunakan untuk memecahkan masalah tersebut adalah motion graphic sebagai media perantara yang tujukan kepada para audience/ masyarakat dalam menyampaikan informasi layanan aplikasi yang nantinya akan di bagikan ke media sosial dan public dalam segi menarik perhatian kepada para audience dengan animasi yang menarik dari aspek-aspek motion graphic.
\end{abstract}

\section{Corresponding Author:}

Multimedia and Network,

Batam State Polytechnic,

J1. Ahmad Yani, Batam Centre, Batam 29461,

Indonesia. Email: Syakilaalatass@ gmail.com

\section{PENDAHULUAN}

Ada beberapa tempat penjualan, dimana mereka tidak mengguakan layanan kasir sebagai alat pembayaran atau transaksi yang jelas, membuat transaksi tersebut terkadang menjadi susah, karena mulai dari pengeluaran pemasukan ,mengatur transaksi penjualan,pembelian, manajemen stok,dan pembukuan keuangan secara digital. saat ini banyak perusahaan seperti tempat café, makan, penjualan baju yang mulai memanfaatkan sistem dan teknologi informasi sebagai komponen utama dalam mencapai keunggulan dalam bersaing. Dengan kemajuan teknologi informasi dan sosial media, pengaksesan terhadap data atau informasi yang tersedia dapat berlangsung dengan cepat, efisien serta akurat. (S Sunarya , 2013). Selain itu dengan adanya media promosi , akan lebih memperluas informasi mengenai aplikasi yang sangat membantu ini. Garuda Kasir Adalah salah satu aplikasi kasir yang didirikan oleh PT.Garuda Cyber Indonesia, yang tidak hanya memiliki 1 produk aplikasi berbasis IT saja , tapi masih banyak lagi aplikasi yang di kembangkan oleh Garuda Cyber Indonsia . Garuda Kasir berlokasi di panam, pekanbaru, Riau . Aplikasi Garuda Kasir ini memiliki 3 tingkatan paket untuk pmbeliannya yaitu Basic, Medium, hingga Enterprise(Garuda Kasir), lalu penggunaaan aplikasi Garuda Kasir tidak hanya digunakan di pc saja, tetapi juga bisa di gunakan di android yang sudah bisa di temui di play store, tercatat 50 pelanggan sudah menggunakan aplikasi ini melalui android, dan untuk di PC sendiri sudah lebih dari 100 pelanggan.

T Teknologi multimedia yang dapat diaplikasikan dalam penyebaran informasi salah satunya adalah motion graphic. Penggunaan motion graphic sebagai pengganti media sosialisasi dianggap lebih efektif karena dapat menyampaikan informasi menjadi lebih menarik dan jelas serta dapat diakses kapan saja dan dimana saja, dengan menggunakan 
penggabungan beberapa teknik dalam penyampaian informasinya didalam motion graphic menjadi lebih komunikatif cukup berperan penting dalam menyebarkan informasi atau gagasan yang ingin disampaikan ke semua Pelanggan.

Berdasarkan permasalahan yang telah disebutkan sebelumnya maka pada Perancangan ini dibuat motion graphic yang berjudul "Perancangan Motion Graphic Iklan layanan Garuda Kasir sebagai media promosi di media sosial " dengan menggunakan metode penelitian Villamil-Molina Pengembangan multimedia akan berhasil baik dengan membutuhkan perencanaan yang teliti, penguasaan teknologi multimedia yang baik, serta penguasaan manajemen produksi yang baik (Binanto, 2013). pemilihan metode ini dikarenakan Villamil-Molina mempunyai struktur organisasi pengembangan yang jelas. Sehingga dalam pembuatannya akan menjadi lebih mudah. Pengembangan Villamil-Molina terdiri dari lima tahap yaitu Development, Preproduction, Production, Postproduction, dan Delivery.

\section{BAB 2 . LANDASAN TEORI}

\section{A. Tinjauan Pustaka}

Perancangan ini dibuat berdasarkan referensi dari beberapa penelitian terdahulu yang berjudul Pembuatan video promosi dengan motion grafik pada gerakan dan aksi untuk pemdidikan indonesia Fandy Adam Satrio dari AMIKOM Yogyakarta. Membahas proses iklan promosi dengan cara gerakan dan aksi dalam konsep pendidikan di indonesia. Serta Perancangan yang berjudul Perancangan Motion Grafis iklan layanan masyarakat tentang perilaku menyimpang lesbian,gay ,biseksual dan transgeneder pada masyarakat Bukittinggi oleh Muthia Humairah dari Universitas Negeri Padang. Membahas pepmbuatan layanan iklan tentang perilaku yang menimpang dan bahayanya dari kegiatan LGBT.

\section{B. Motion Graphic}

Menurut Michael Betancourt di dalam artikelnya yang berjudul berjudul "The Origins of Motion Graphics" motion graphic adalah penggabungan dari film, video, fotografi, ilustrasi, animasi dan musik. Termasuk di dalamnya yaitu tipografi dan grafis yang dapat terlihat sebagai titles untuk film, pembuka program televisi, bumper dan elemen-elemen grafis yang muncul di televisi. Motion graphic merupakan gabungan dari potongan elemenelemen desain/animasi yang berbasis pada media visual yang menggabungkan bahasa film dengan desain grafis, dengan memasukkan elemen yang berbeda-beda seperti 2D atau 3D. Media yang dimasukkan berupa still images atau gambar diam, dengan format gambar bitnamp maupun vector, dan data video manapun.

\section{Iklan}

iklan komersial adalah iklan yang bertujuan mendukung kampanye pemasaran suatu produk atau jasa. Sedangkan iklan non-komersial memiliki jenis yang banyak, termasuk iklan tentang pencarian orang hilang, iklan layanan masyarakat,tentang lowongan pekerjaan, iklan pencarian jodoh, dll. Namun dalam perancangan penelitian ini,saya hanya akan membahas tentang iklan nonkomersial yang bertujuan untuk kepentingan atau pelayanan masyarakat (public service).

\section{Media Sosial}

media sosial merupakan suatu sarana bagi konsumen untuk berbagai informasi teks, gambar, video, dan audio dengan satu sama lain dan dengan perusahaan dan sebaliknya. Menurut pemaparan diatas media sosial adalah sebuah sarana bagi pelanggan, konsumen, dan pengguna internet untuk berbagi berupa media visual, audio

\section{E. Metode Villamil-Molina}

Metode pengembangan sistem yang akan digunakan di dalam perancangan kali ini yaitu Multimedia Development Life Cycle (MDLC).dengan menggunakan Metode Villamil-Molina akan bekerja lebih baik jika menggunakan perencanaan yang rinci, menguasai teknologi multimedia yang baik, serta penguasaan manajemen produksi yang baik. Pemilihan metode disamping itu juga ada uji tahap Alfa dan beta Villamil-Molina pada perancangan ini dikarenakan VillamilMolina mempunyai struktur organisasi pengembangan yang jelas. Sehingga dalam pengembangannya akan menjadi lebih mudahdan praktis untuk di jelaskan. Pengembangan VillamilMolina sendiri terdiri dari lima tahapan yaitu Development, Preproduction, Production, Postproduction, dan Delivery. Adapun Tahapan-tahapan metode ini sebagai berikut :

\section{Development}

Pada tahap development konsep perancangan aplikasi multimedia akan dimulai pengembanganya berdasarkan ide yang telah ditentukan. Setelah ide ditentukan maka tahap selanjutnya yaitu menentukan tujuan dan sasaran serta kepastian jaminan pembiayaan produk. 


\section{Journal of Applied Multimedia and Networking (JAMN)}

Vol.4, No.2, Desember 2020

2. Preproduction

Pra-Production adalah tahapan awal dalam perencanaan pembuatan multimedia yaitu dengan membuat naskah, storyline dan pembuatan storyboard.

\section{Production}

Dalam tahapan ini berisi uraian proses produksi dari pengembangan yang terdiri dari animasi (animating), editing, dan rendering sebuah produk multimedia sehingga menjadi sebuah produk utuh yang siap untuk dilakukan tahap pengujian.

\section{Post Production}

Post-Production adalah pengembangan produk multimedia memasuki tahapan pengujian alfa dan beta. Namun penguji terlebih dahulu melakukan evaluasi dengan memperhatikan aspek-aspek yang ditentukan.

\section{Delivery}

Tahap delivery merupakan tahap akhir dari pengembangan produk. Delivery dapat menggunakan beberapa cara, yaitumelakukan pengemasan

produk, melakukan presentasi individual atau kelompok, dan publikasi produk melalui internet. Pengemasan produk dapat dikemas melalui CD/DVD dan publikasi produk melalui internet dapat dilakukan pada berbagai sosial media online. Semua tahapan ini memerlukan perhatian khusus, terutama dalam kaitannya logistik pengiriman.

\section{METODE PERANCANGAN}

Tahapan dalam metode Villamil-Molina terbagi menjadi lima bagian development, preproduction,Production, Post production, dan delivery, Tahap-tahap pengembangan Villamil-molina seperti ditunjukkan pada Gambar 1.

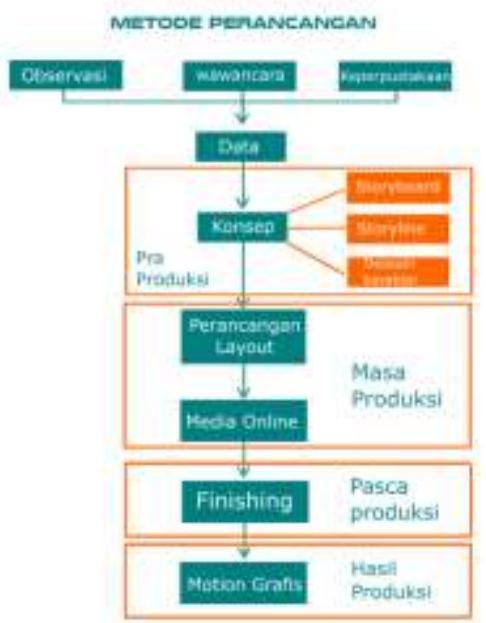

Gambar 1. Metode perancangan Villamil-molina

\section{Development}

Pada bagian development ini akan menjelaskan mengenai konsep dan tujuan dari motion graphics, target pengguna motion graphics yang akan dijelaskan dalam bentuk naratif (sinopsis). Pada tahap pembentukan ide yaitu dimulai dengan memnentukan ide judul

"Iklan layanan Motion grafis Aplikasi Garuda Kasir" yang kemudian isi konten menampilkan mengenai Tata cara penggunaan aplikasi dari Garuda Kasir tersebut dan keuntungan dari menggunakan aplikasi tersebut .Tujuan dari perancangan ini yaitu terbentuknya Motion graphic yang dapat digunakan untuk memperkenalkan Aplikasi Garuda Kasir kepada Client / audience dan menjadi salah satu media promosi. 


\begin{tabular}{|l|l|}
\hline Judul & $\begin{array}{l}\text { Perancangan motion } \\
\text { graphic iklan layanan } \\
\text { aplikasi Garuda Kasir } \\
\text { sebagai media } \\
\text { promosi }\end{array}$ \\
\hline Durasi & $1-2$ Menit \\
\hline Tujuan & $\begin{array}{l}\text { terbentuknya Motion } \\
\text { graphic yang dapat } \\
\text { digunakan untuk } \\
\text { memperkenalkan } \\
\text { Aplikasi Garuda Kasir } \\
\text { kepada Client / audience } \\
\text { dan menjadi salah satu } \\
\text { media promosi. }\end{array}$ \\
\hline Hideo dengan format \\
.MP4 \\
\hline
\end{tabular}

2. Pre Production.

Proses yang dilakukan pada tahap ini adalah dengan menulis narasi, mendesain sketsa kasar pada asset, membuat storyboard untuk mengetahui gambaran sketsa scene pada motion graphic yang dibuat, mempersiapkan perangkat keras dan perangkat lunak yang dibutuhkan, dan menentukan jadwal pelaksanaan.

a. Desain Sketsa Karakter

Pada Tahap ini dilakukan pembuatan desain sketsa yang akan digunakan pada video motion graphic ini. Karakter yang digunakan pada motion graphic ini memiliki 2 karakter yaitu :

- Karakter pemilik perusahaan dan pemilik aplikasi garuda Kasir

- Karakter cewek di perushaan yang sebelum dan sesuadah nantinya menggunkan aplikasi tersebut

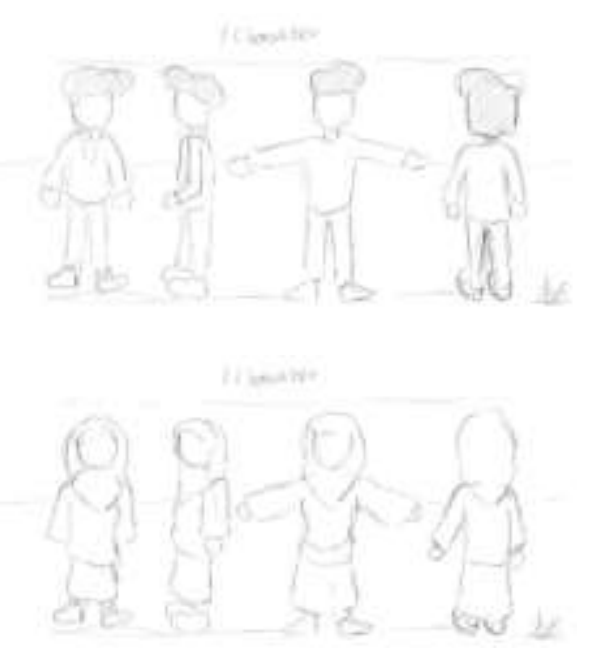

Gambar : 2 Gambar karakter Animasi.

b. Storyline.

Pada tahap ini merupakan gabungan dari unsur-unsur untuk membentuk cerita sehingga menjadi kerangka utama cerita ini. 
Journal of Applied Multimedia and Networking (JAMN)

Vol.4, No.2, Desember 2020

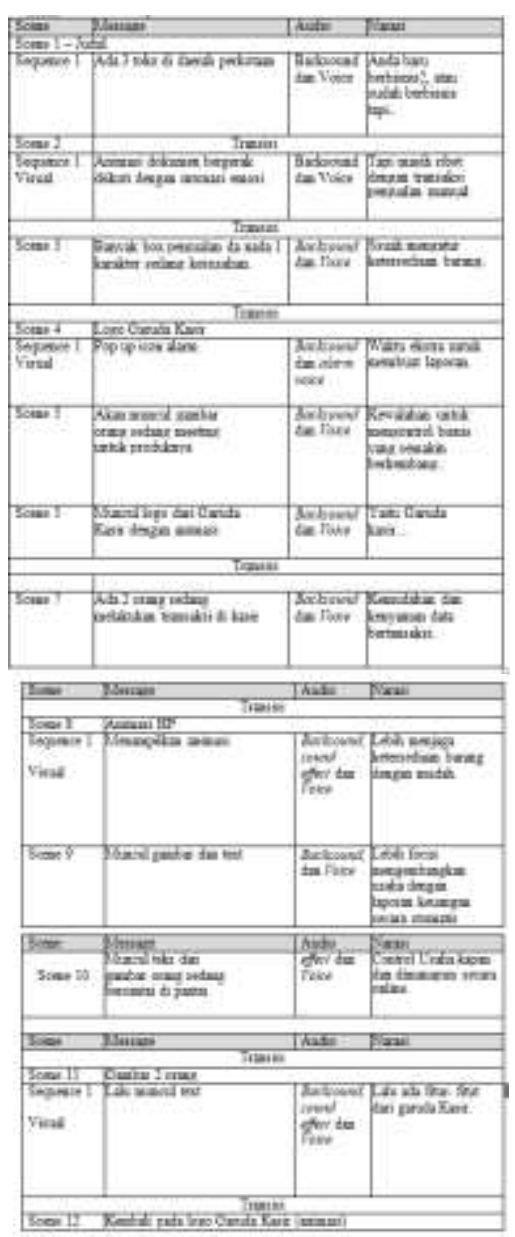

c. Perancangan Storyboard

Kegiatan yang dilakukan pada tahap ini yaitu dengan dilakukanya pembuatan storyboard yang berfungsi untuk menentukan alur atau jalan cerita video profil ini agar tersusun rapi dan jelas.Desain Storyboard ini terdiri dari 13 Scene. Desain storyboard disajikan pada Gambar 3.

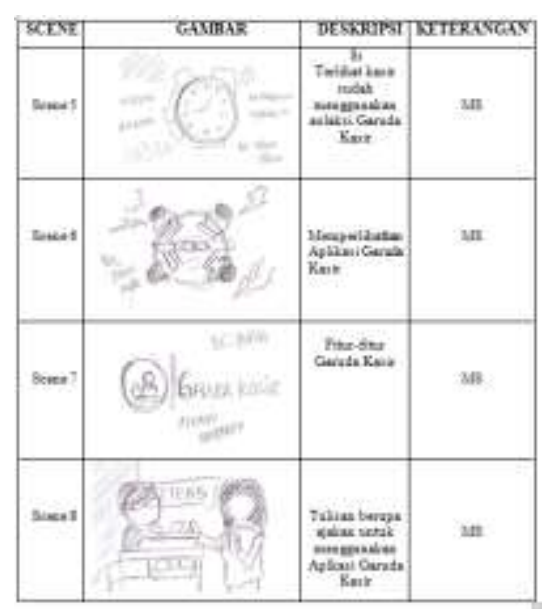




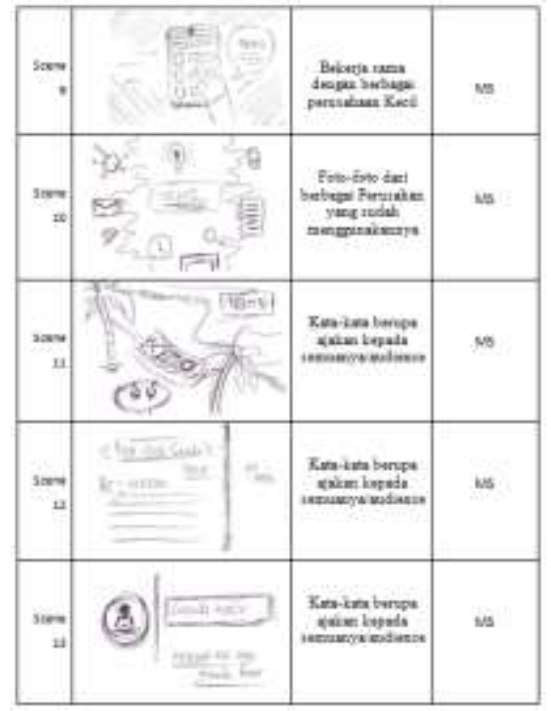

d. Perangkat yang digunakan

Dalam suatu proses perancangan pembuatan karya multimedia dibutuhkan persiapan spesifikasi Hardware dan software yang akan digunakan seperti pada table 3 .

Tabel 2. Spesifikasi Hadware dan Software

\begin{tabular}{|c|c|}
\hline Nama Perangkat & Keterangan \\
\hline Hardware & $\begin{array}{ll}- & \text { Komputer } \\
- & \text { Kapasitas } \\
& \text { Mmeori Ram } \\
& 8 \mathrm{~Gb} \\
& \text { Hardisk 1 TB } \\
- & \text { Microfon }\end{array}$ \\
\hline Software & $\begin{array}{ll}\text { - } & \text { Windows } 10 \\
\text { - } & \text { Adobe After } \\
\text { Effect CC } & \text { C016 } \\
\text { - } & \text { Adobe } \\
& \text { Premiere CC } \\
\text { - } & \text { Adobe } \\
\text { Illustrator } \\
\text { CC 2016 } \\
\text { Adobe } \\
\text { Photoshop } \\
\text { 2016 }\end{array}$ \\
\hline
\end{tabular}

\section{HASIL DAN PEMBAHASAN}

\section{Production}

Proses yang dilakukan pada tahap ini adalah melakukan tracing dari sketsa yang sudah di buat, pengembangan animasi dari desain grafis yang sudah dibuat, pemilihan Tracing, editing dan rendering menggunakan Adobe Ilustrator CS6, Adobe Premiere CS6 Pro , Adobe After Effect CS6

a. Tahap Produksi 


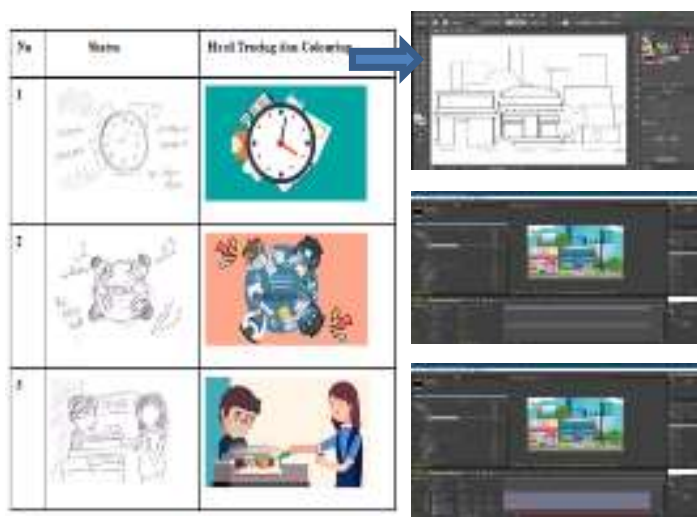

Gambar 5. Hasil Tracing Colouring, dan rendering

\section{Post Production.}

Pada tahap Post Production ini dilakukan analisis terhadap video profil Motion graphic yang telah dibuat dengan melakukan pengujian alfa testing dan beta testing sesuai dengan aspek-aspek yang terkait dengan cara Melakukan sesi wawancara langsung. Di dalam Pengujian alfa ini dilakukan pengujian terhadap 1 ahli yaitu ahli media. Didalam pengujian alfa pada ahlinya terdiri dari 2 orang yang melakukan pengujian mengenai video profil ini. Pada ahli informasi dipilih berdasarkan dari pihak Pembuat dari aplikasi Garuda kasir yang memahami mengenai informasi keseluruhan yang terdapat di aplikasi garuda kasir, sedangkan untuk ahli media dipilih berdasarkan dari orang-orang yang memahami mengenai unsurunsur mediayang terdapat pada Video iklan layanan moton graphic ini. Adapun aspek- aspek yang terdapat pada wawancara untuk para ahli informasi yaitu latar belakang, kompetensi keahlian, keunggulan, kegiatan dan promosi sedangkan aspek-aspek yang terdapat pada kuesioner untuk ahli media yaitu karakter, teks, warna, gambar, animasi, suara, video

\section{Delivery}

Pada tahap ini yaitu tahap Delivery, akan dilakukan proses pengeman sebuah produk yaitu berupa Video Motion Graphic berformat MP4 dengan durasi waktu 2 menit, dan di demo kan secara langsung kepada client dimana di pertemukan dalam 1 ruangan.

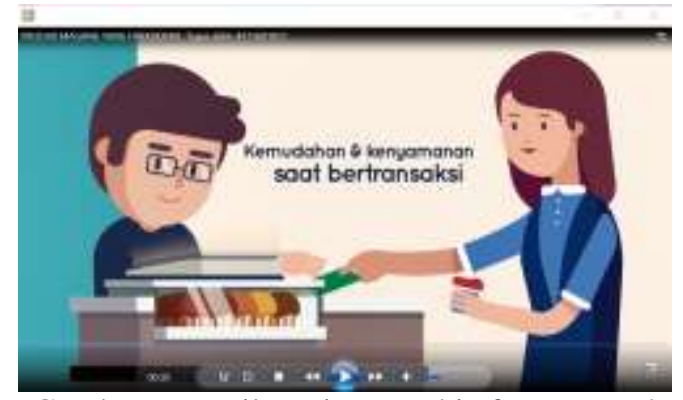

Gambar 6. Hasil motion graphic format MP4

1. Pengujian Alfa

Hasil tes uji alfa yaitu merupakan hasil pengujian awal pada produk yang telah dibuat untuk para ahli di bidang informasi dan media, sehingga dapat diketahui sekurang-kurangnya yang terdapat pada video iklan layanan motion graphic ini serta saran yang diberikan oleh para ahli harus di perbaiki langsung dalam pembuatan video profil ini setelah melakukan sesi wawncara. Setelah dilakukan pengujian alfa maka dapat di peroleh hasil keseluruhan aspek kepada ahli yaitu $100 \%$ pada ahli informasi dan $90 \%$ pada ahli media. Sesuai dengan hasil wawancara bahwa Seluruh jawaban ahli informasi dan hampir seluruh ahli media sudah menyutujui pembuatan video iklan layanan motion graphic ini telah memenuhi standar dari keseluruhan aspek yang disajikan dan selanjutnya dapat dilakukan pengujian beta. 


\section{Pengujian Beta}

Pengujian beta merupakan pengujian lanjutan dari tahap pengujian alfa yang dipergunakan untuk mengambil keputusan tentang kelayakan sebuah produk sebagai media promosi yang nantinya akan dilihat oleh para client setelah melakukan pengujian

Pada beta maka dilakukanlah analisis kelayakan produk dengan melakukan sesi wawancara juga secara langsung oleh pihak client. Hasil wawancara yang di peroleh ada beberapa unusr yang akan di runbah sesuai dengan jawaban yang di berikan atau saran oleh para client.

3. Anlisis Kelayakan Produk.

Analisis kelayakan produk merupakantahapan dimana pada tahap ini akan didapatkannya suatu kesimpulan tentang kelayakan dari produk iklan layanan ini dari tahapan beta testing yang sudah di evaluasi oleh aspek unsur tampilan, Pengetauhan serta pemahaman. Berikut hasil dari wawancara kepada pihak client , tentang produk video Iklan layanan aplikasi garuda kasir yang memiliki beberapa point penting sebagai kelayakan pada Produk

Tabel 3. Wawancara kepada Client Untuk hasil dari Uji Beta

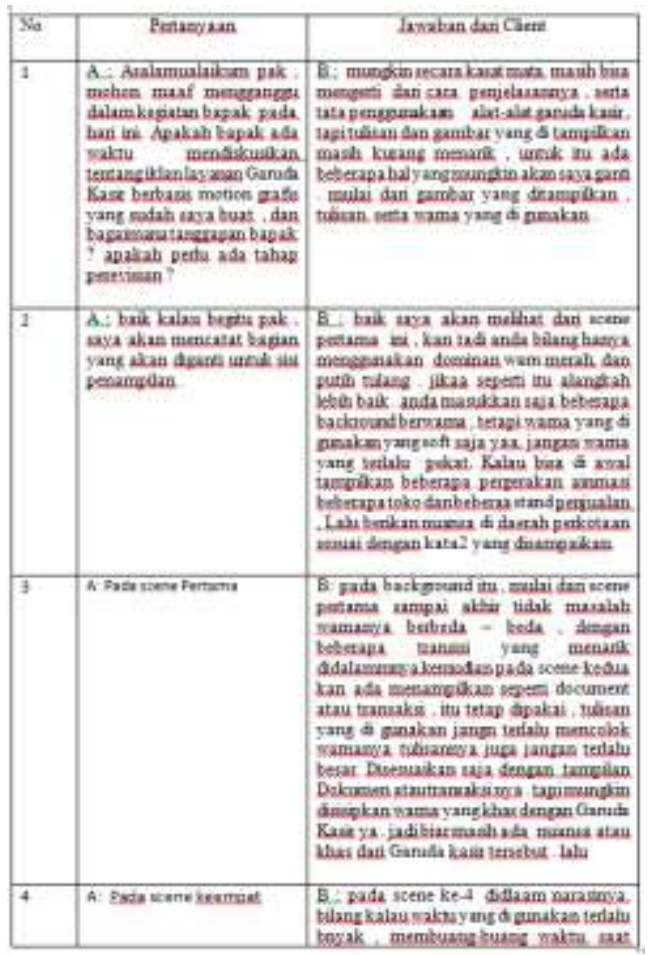




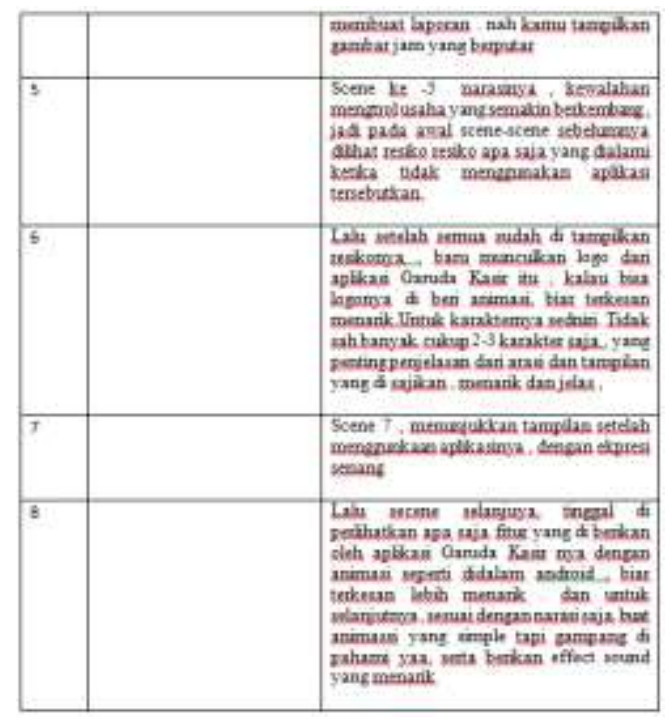

a. Unsur Tampilan

Berdasarkan dari unsur Tampilan dengan hasil wawancara ,Ada beberapa tamppilan yang nantinya dimintai perbaikan karena client lebih nyaman apabila gambar yang tampilkan tersekesan menarik dengan di masukkan beberpa warna lain yang tidak terlalu mengacu pada warna dari ciri khas Aplikasi Garuda Kasir, serta animasi yang perlu di tambah agar ebih mambuat client lebih tertarik pada saat meliat iklan layanan Aplikasi Garuda kasir.

b. Pengetauhan

Berdasarkan dari segi Pengetauan yang terdiri dari beberapa pertanyaan setelah hasil wawancara , bahwa sudah hamper 99\% client sudah memahami dan mengetauhi informasiinfomasi pada Aplikasi Garuda kasir yang berbasis Motion Graphic ini.

c. Pemahaman

Berdasarkan dari segi Pengetauanyang terdiri dari beberapa pertanyaan setelah hasil wawancara.client sepenihnya sudah, sangat ,memahami keseluruhan secara baik mengenai penyajian video motion graphic, informasi Aplikasi Garuda Kasir serta ketertarikan menawarakan Aplikasi ini kepada client yang lain.

\section{KESIMPULAN}

Berdasarkan penjelasan mengenai pembuatan motion graphic pada Iklan Layanan aplikasi garuda kasir menggunakan metode Villamil-Molina yang terdiri dari tahapan development, preproduction, production, post production dan delivery. Video profil motion graphic ini telah layak menjadi media Iklan Layanan aplikasi garuda kasir dengan hasil berupa video berdurasi 2 menit dengan format MP4. Berdasarkan hasil analisis berupa wawancara oleh pihak ahli media dan dari pihak clinet yang terkait maka Video motion graphic dari iklan layanan aplikasi garuda kasir ini telah memenuhi indikator kelayakan yaitu dari unsur tampilan sebanyak $90 \%$, unsur pengetahuan sebanyak $99 \%$, unsur pemahaman sebanyak $100 \%$. dan hasil dari wawancara tentang unsur tampilan yang belum memenuhi kriteria, sudah di buat sedemikian rupa sesuai yang di minta oleh client, jadi sudah ada perubahan agar menjadi video iklan layanan motion graphic yang layak untuk di tampilkan

\section{DAFTAR PUSTAKA.}

[1]. Prabawa, Angga, 2014, Motion Grafis http://www.academia.edu/8601077/ Motion_Grap-hic, diakses 30 oktober 2019.

[2]. Garuda Cyber Indonesia. https://garudacyber.co.id/, diakses, 12 oktober 2019

[3]. Garuda Kasir, https://kasir.garudacyber.co.id/, diakses, 12 oktober 2019 
Journal of Applied Multimedia and Networking (JAMN)

$\mathrm{V}_{1}$ ol.4, No.2, Desember 2020

[4]. Wasruhan. 2013. Pengertian adobe after effects. http://wasrukhan.blogspot .com/2013/11-/pengertian-adobe-after-effects.html, diakses tanggal 23 oktober 2019

[5]. Wasruhan. 2013. Pengertian adobe premiere pro. http://wasrukhan.blogspot.com/2013/-11/pengertian-adobepremiere-pro.html, diakses tanggal 23 oktober 2019

[6]. Adjie. 2013. Artikel Pengertian Adobe Audition. http://bontotadjie.blogspot.com/2013/-01/artikel-pengertianadobe-audition.html, diakses tanggal 23 oktober 2019

[7]. Carole, Gray, J. \& Malins, 2004. Visualizing Research: A Guide to the Research Process in Art and Design. Burlington: Ashgate Publishing Company.

[8]. Anggraini, Yunita. 2017. “Analisis Dan Implementasi Motion Grafis Iklan Layanan Masyarakat Dengan Metode Semiotika Peirce". Multimedia dan jaringan. Politeknik Negeri Batam. Binanto, Iwan. 2010. Multimedia Digital Dasar Teori dan Pengembangannya.

[9]. Kho, D. (2017). Pengertian Skala Likert dan Cara Menggunakan Skala Likert. Retrieved from http://teknikelektronika.com/

[10]. Yesty, Desca Refita Putri. 2017. Pembuatan Motion graphics Sebagai Media Sosialisasi dan Promosi untuk Aplikasi Mobile Trading Online Mandiri Sekuritas. Jurnal Ilmiah Manajemen Informatika dan Komputer. 1(2): 858

[11]. Sugiyono. 2013. Metode Penelitian Kuantitatif, Kualit 